\title{
Residência multiprofissional e formação em saúde: análise das relações interprofissionais
}

\author{
Michele Cristina de Carvalho, Rosana Aparecida Salvador Rossit
}

\section{Resumo}

Introdução A prática interprofissional caminha ao encontro do trabalho compartilhado, integrativo e colaborativo; corrobora com a troca de experiências entre os envolvidos e com o desenvolvimento de competências, tanto relacionadas à singularidade das profissões quanto com as colaborativas (PEDUZZI, 2013). Além disso, possui importante papel no processo de promoção da saúde, na prevenção de danos e na reabilitação; estabelecendo o cuidado integral e caminhando junto às diretrizes e princípios do Sistema Único de Saúde, principalmente no que tange a integralidade do cuidado. É neste contexto que a ideia de trabalho interprofissional vem se destacando nos cenários organizacionais. As teias formadas entre o interprofissionalismo e a prática colaborativa tendem a levar o indivíduo para o olhar ampliado e integrado, articulando ações, outrora já conhecidas, com a construção de novas práticas clínicas, fomentando o respeito e a confiança entre os envolvidos (SILVA et al, 2015). Contudo, ainda existem interrogações sobre como os profissionais percebem a dinâmica de trabalho e as relações profissional-profissional e profissional-paciente. Objetivo Analisar a percepção de profissionais de saúde sobre o trabalho em equipe interprofissional e a prática colaborativa. Métodos Trata-se de uma pesquisa descritiva, com abordagem quantitativa e qualitativa. Desenvolvido em um Hospital Filantrópico do Litoral de São Paulo. A população compreende os profissionais envolvidos diretamente com as Residência Multiprofissional e Residência Médica em Ortopedia e Traumatologia. Participam da pesquisa os residentes de primeiro, segundo e terceiro ano (este último apenas da residência médica), preceptores e tutores, das áreas de enfermagem, farmácia, fisioterapia e medicina. O número total da amostra é de quarenta e oito profissionais $(n=48)$. A coleta dos dados refere-se aos períodos de Setembro a Novembro de 2017, realizada mediante a aplicação de instrumentos com dados de caracterização e a Readiness Interprofessional Learning Scale (RIPLS). A versão da RIPLS validada para o Brasil (PEDUZZI, 2015) é constituída por 27 assertivas em escala Likert de cinco pontos e estruturada em três fatores: Trabalho em equipe e colaboração com 14 assertivas; Identidade profissional com oito assertivas; e, Atenção à saúde centrada no paciente com cinco assertivas. Os dados de caracterização e RIPLS foram organizados em planilhas do Excel@, analisados estatisticamente e apresentados em média e gráficos. Após análise dos dados obtidos com a RIPLS, será realizado grupo focal para explorar em profundidade aspectos emergentes desta análise inicial, acerca da relação interprofissional, seus desafios e potencialidades. $O$ projeto foi apresentado aos responsáveis pelos programas de residência multiprofissional e residência médica em ortopedia e traumatologia e ao núcleo de ensino e pesquisa do hospital. Foi elaborada uma carta de anuência pela pesquisadora, a qual foi assinada pelos responsáveis acima citados e anexada ao projeto no momento de submissão ao comitê de ética em pesquisa (CEP). O projeto foi aprovado pelo CEP sob o parecer 2.034.627. São seguidas as normalizações da Resolução 466/12 referentes às normas éticas de pesquisas envolvendo seres humanos (BRASIL, 2012). Resultados preliminares Até o momento 34 participantes $(70,8 \%)$ consentiram em participar da pesquisa e responderam ao instrumento: 13 residentes do programa multiprofissional $(38,2 \%), 16$ residentes médicos $(47,1 \%)$, 4 preceptores $(11,8 \%)$ e apenas 1 tutor $(2,9 \%)$ da área da fisioterapia. Destes, 13 são do sexo feminino $(38,2 \%)$ e 21 do sexo masculino (61,8\%). Observa-se que há o predomínio do sexo feminino no programa de residência multiprofissional, correspondendo a 76,9\% dos indivíduos deste programa (todos os residentes do multiprofissional participaram da primeira etapa); em contrapartida, dos instrumentos coletados com a residência médica, todos representavam o sexo 
ISSN 2179-6750

masculino. Em relação ao ano de residência, do programa multiprofissional, sete $(53,8 \%)$ são do primeiro ano (R1) e seis $(46,2 \%)$ são do segundo ano (R2). Na residência médica, cinco $(31,3 \%)$ eram do primeiro ano, cinco $(31,3 \%)$ do segundo ano e seis $(37,4 \%)$ do terceiro ano (R3). Dos 34 participantes, 10 residentes multiprofissionais $(76,9 \%), 14$ residentes médicos $(87,5 \%), 3$ preceptores $(75 \%)$ e o tutor referiram já ter trabalhado com profissionais de outras áreas da saúde, antes de estarem vinculados aos programas das residências. Quando investigado sobre a participação em cursos, colóquios e/ou palestras que abordavam o trabalho em equipe e a formação em saúde, 9 residentes multiprofissionais, 4 residentes médicos e 3 preceptores responderam afirmativamente. Os outros 18 participantes $(52,9 \%)$ responderam que nunca haviam participado. Os dados obtidos da RIPLS foram analisados considerando-se as médias das pontuações em cada assertiva e a classificação por cores, pontuações e providências. As cores são representadas pelo Vermelho com pontuação de 1,0 a 2,33, sinalizando "zona de perigo", representando percepção negativa e a necessidade de mudanças imediatas sobre o que está sendo pesquisado; Amarelo com pontuação de 2,34 a 3,67, sinalizando "zona de alerta", dificuldades que demandam mudanças sem o caráter de urgência"; e, verde com pontuação de 3,68 a 5,0, sinalizando "zona de conforto" , percepção positiva, denotando êxito no aspecto investigado (Adaptado de PEREGO, 2015). De acordo com a análise dos dados da RIPLS, as assertivas referentes ao fator 1 (trabalho em equipe e colaboração) com média geral de 4,60 e ao fator 3 (atenção à saúde centrada no paciente) com média geral de 4,70, classificam-se na cor verde, representando uma percepção positiva dos participantes em relação à estes aspectos. Contudo, o fator 2 (identidade profissional) com média geral de 3,10, mostrou que na percepção dos participantes ainda existem dificuldades, todavia sem necessidade de mudanças urgentes, sendo classificada pela cor amarela. Na residência multiprofissional, as assertivas A18 ("preciso adquirir muito mais conhecimentos e habilidades que estudantes de outras profissões da saúde"), A19 ("eu me sentiria desconfortável se outro estudante da área da saúde soubesse mais sobre um tópico do que eu") e A20 ("serei capaz de usar frequentemente o meu próprio julgamento no meu papel profissional") foram destaque de alerta para o fator. As médias foram 3,62; 3,15 e 2,69 respectivamente. Na residência médica as assertivas A17 ("a função dos demais profissionais da saúde é principalmente apoio aos médicos"), A18, A19, A20 e A21 ("chegar a um diagnóstico será a principal função do meu papel profissional") também se destacaram em alerta. As médias foram 3,38; 2,44; 3,63; 2,63 e 3,06 respectivamente. Por fim, na preceptoria e tutoria as assertivas que ganham destaque para a cor amarela foram A20, A21 e A22 ("minha principal responsabilidade como profissional será tratar meu paciente"); tendo suas médias em 2,40; 3,20 e 3,60. Considerações preliminares. Por meio dos resultados iniciais é possível identificar entraves na perspectiva dos participantes sobre qual seria a sua identidade e o seu papel profissional- indivíduo e profissional-grupo. Neste sentido, torna-se interessante pensar em programas de aprimoramento e desenvolvimento de competências, de modo a ampliar a compreensão sobre a formação interprofissional em saúde e a prática colaborativa, bem como evidenciar seus significados e suas importâncias para o cuidado integral e longitudinal.

Descritores: Educação em Saúde, Relações Interprofissionais, Comportamento Cooperativo 